\title{
Forum
}

\section{Akademiskt och professionellt skrivande inom socionomutbildningen}

Susanna Lundberg, lektor i socialt arbete vid Institutionen för socialt arbete på Malmö universitet.

Kontakt: Susanna.lundberg@mau.se

\section{Inledning}

Professionella socionomers texter avgör om barn får stanna med sina föräldrar, om missbrukare får livräddande behandling och om barnfamiljer har råd att fira jul. De färdigheter i dokumentation och systematiskt välfärdsarbete som diskuteras i det här temanumret grundläggs under professionsutbildningarna. Utbildningarna måste hjälpa studenterna att förstå skrivande och dokumentation som något djupare än att korrekt använda regler.

Jag kommer i artikeln att diskutera socionomstudenters skrivande ur ett textteoretiskt perspektiv, och mer specifikt se på utredningar av barn $i$ fara, en process och texttyp som är vanlig inom socialtjänsten och ställer specifika krav på både interaktion och skrivande. Jag menar att relationerna mellan det akademiska skrivandet och det professionella borde uppmärksammas mer för att tydliggöra de akademiska färdigheternas roll inom professionen.

\section{En textteoretisk ram}

För att förstå skrivandets roll inom socionomyrket behöver vi ta hjälp av språkforskare som undersöker utveckling av akademiska färdigheter. I en sådan ram ses akademiskt skrivande som något utöver att följa skriftspråksnormerna. Academic literacies (Lea \& Street, 1998) är ett begrepp som avser att lyfta diskussioner kring de akademiska praktikerna läsning och skrivande till ett resonemang om hur vi närmar oss 
tankar och kommunikation som hela människor i komplexa relationer med makt och olikhet med högst olika syften för vårt arbete. Pluraländelsen literacies pekar på att det inte finns ett sätt att vara läs- och skrivkunnig inom akademin, utan många sätt att använda läsande och skrivande. Lea och Street kritiserar de äldre traditioner som studerar skrivförmågor som isolerade från andra akademiska förmågor, och som färdigheter som kan läras in och rättas till. De bygger vidare på en tradition som kallas academic socialization (se t.ex. Wingate \& Tribble, 2012) där fokus ligger på att kunskapsutveckling inom högre utbildning påverkas av att studenters och lärares sociokulturella bakgrund ofta skiljer sig åt, och att ju större skillnad i detta avseende, desto svårare är det för studenter och lärare att förstå varandra. Maktrelationerna mellan lärare och studenter, och även mellan olika grupper av studenter, är viktiga att ha med sig när man diskuterar högskolepedagogik i allmänhet och studenters språkutveckling i synnerhet, menar de.

Det perspektiv som Lea och Street (1998) förespråkar kallas academic literacies och lyfter fram att akademin inte kan ses som en homogen kultur utan är en mångfald av sociala praktiker. De menar att studenters skrivande och lärande bör betraktas på epistemologisk och identitetsnivå, till exempel som en fråga om "vad ska en som jag ha den här typen av kunskap till?" De akademiska miljöerna måste förstås som diskurs- och maktfält där hierarkiska strukturer avgör vad som är central eller mindre central kunskap och hur denna kunskap ska förmedlas, formuleras och bedömas. För studenterna blir det avgörande att kunna växla mellan de olika akademiska miljöernas literacies, för att i slutänden skapa sig en egen, autonom literacy. Växlandet mellan olika akademiska miljöer som studenter gör när de läser olika ämnen inom sin utbildning skapar en diskursmedvetenhet som hjälper studenterna till sin autonoma literacy, i den mån de olika miljöerna respekterar varandras olikheter som likvärdiga.

Men det medvetna växlandet mellan ämnes- och skrivtraditioner förutsätter att koderna inom respektive tradition tydliggörs för studenterna. Sofia Asks undersökning av skrivande inom högskolan tyder på att det inte alltid är fallet (se även Graff, 2003, och Lea \& Street, 1998). Hon lyfter fram att många studenter upplever att de språkliga koderna präglas av inkongruens, otydlighet och osynlighet, och hon kallar dem hemlighetsstrukturer (Ask 2007, s. 165). Graff menar till och med att "Schooling obscures the life of the mind" (Graff, 2003, se titeln). Studenterna i Asks undersökning uppfattar att de akademiska koderna är ogenomträngliga och inte syns förrän någon bryter mot dem, vilket ger dem dåligt självförtroende och en otrygg lärandemiljö.

Ask talar om tre grundläggande akademiska skrivkompetenser, nämligen: 
- operationell kompetens: språkriktighet, styckesindelning, logisk struktur

- diskursiv kompetens: stil, referenser

- kritisk kompetens: analys, kritiskt tänkande.

Att Ask och andra språkforskare kallar kritiskt tänkande och förmåga till analys för skrivkompetenser kan kanske förvåna akademiker från andra fält, men de är centrala akademiska färdigheter som endast i begränsad mån skiljer sig åt mellan olika ämnen. Text och skrivande är de verktyg där kompetenserna övas och kommer till uttryck. Kompetenserna handlar om textens relation till andra texter och textens funktion i ett socialt och professionellt sammanhang.

Ask menar att högskolevärlden låter studenterna lägga fokus på fel nivå:Hon visar att nybörjarstudenterna lägger så mycket krut på de operationella och diskursiva kompetenserna att de "i sin strävan att följa kraven på formalia fjärmas [...] från att reflektera och tänka kritiskt" (Ask, 2007, s 157). När nybörjarstudenter frågar sina lärare om de "får ha med egna funderingar" kan det tolkas som en begynnande kritisk kompetens, men utan den akademiska språkdräkt som förväntas (ibid.). Att då rödmarkera formuleringar som "jag tycker", "enligt mig" och så vidare, hindrar det kritiska tänkandet snarare än det gynnar formen.

Ask påpekar också att olika kompetenser ofta utvecklas i otakt. Texters innehåll och genre påverkar till exempel ordval, meningsbyggnad och struktur. Därmed kan tillägnandet av en ny diskurs eller ämnestradition ge upphov till osäkerhet eller olika uppfattningar om ordval och textstruktur utan att det behöver vara tecken på att studentens operationella kompetens eller kompetens inom andra diskurser brister.

De djupgående skrivkompetensernas plats inom utbildningen, och lärarnas stöd i processen är förutsättningar för att utveckla den ämnesspecifika och sedermera även den autonoma literacy som är utbildningens mål. Den undersökning som Ann Blückert (2010) har gjort av juridiklärares respons på studenters texter stödjer Asks slutsats om studenters förvirring på så sätt att fokus i responsen i stor utsträckning ligger på textens lokala nivåer, och att frågor om struktur, genre och kommunikativa funktioner kommenteras i betydligt mindre utsträckning. Blückert har vid en kvantitativ granskning av lärarnas kommentarer funnit att över tre fjärdedelar av de undersökta lärarkommentarerna gällde textens yta, till exempel stavning, referensformalia och ordval, medan kommentarer om innehåll och genre utgjorde 10 procent och kommentarer om struktur/disposition samt textens syfte och mottagare sammanlagt utgjorde 3 procent av kommentarerna (Blückert, 2010, s. 157). Om syftet med en text är att reflektera och kritiskt granska men responsen handlar om språkets yta kan de mest avgörande språkfärdigheterna framstå som delar av en hemlighetsstruktur.

För att kunna stödja studenternas utveckling mot ett funktionellt akademiskt och professionellt skrivande måste alla högskoleutbildningar, och särskilt de mot välfär- 
dens professioner, lägga mer vikt vid att aktivt stödja utvecklingen av de akademiska textfärdigheterna. För det krävs en kollegial diskussion och att begreppsliggöra de verktyg som krävs, så att lärare och uppsatshandledare blir bättre på att uppmärksamma studenters ämnesspecifika skrivproblem och hjälpa till att lösa dem. Det kollegiala och pedagogiska metaspråket för textstruktur och skrivande är i dag alltför abstrakt för undervisande lärare utanför språkutbildningarna och det bidrar till att förstärka hemlighetsstrukturerna.

\section{Vilka färdigheter och textkompetenser behöver socionomer?}

Socionomstudenter och andra inom professionsutbildningar har speciella förutsättningar på minst två sätt som komplicerar vägen till en autonom literacy. Dels finns studenternas akademiska miljö huvudsakligen inom en och samma institution, men en institution som i sig utgör en heterogen mångvetenskaplig miljö. Olika kurser eller lärare inom utbildningen använder skrivande och kunskaper på olika sätt utan att studenterna förstår orsaken till likheter och skillnader. Dels förhåller sig studenterna på professionsutbildningar i hög grad till en konkret arbetsmarknad som ställer outtalade men viktiga krav. När kraven från professionen är outtalade är de svåra både för högskolelärare och studenter att förhålla sig till och jämföra med kraven från akademin.

Det viktiga för en professionsutbildning är att se studenters skrivande inte bara eller ens främst som en inomakademisk fråga utan att växla perspektiv och se skrivandet ur studenternas perspektiv som framtida professionella. Både studenter och lärare behöver förstå både att och hur det akademiska skrivandet kan bidra till de professionella färdigheterna. Lärare inom högskolan måste förstå professionens krav för att kunna integrera dessa med akademins krav.

Den här artikeln uppehåller sig vid skrivande inom socionomprogrammet, men professionella tjänstemän överallt skriver i tjänsten. Högskolelagen stipulerar att alla studenter ska kunna "utbyta kunskaper även med personer utan specialkunskaper inom området" (SFS 2006:173 8 §), och de lagar som rör välfärdsområdet understryker krav på tydligt, kommunikativt och precist skrivande. Välfärdsprofessionernas texter riktar sig både till klienterna och inåt till institutionerna själva, och den professionelle måste därför både förhålla sig till klientens situation, till lagen och till andra klienter i nutid och framtid. Skrivandet är i många avseenden själva arbetet, och är därmed värd mer uppmärksamhet än att reduceras till en fråga om skrivkonventioner och formell korrekthet.

Även om frågan om utbildning mot skrivande inom välfärdens professioner gäller alla samhällsvetenskapliga programutbildningar i någon mån, menar jag att socionomutbildningen är speciell i viktiga avseenden. Jag vill här göra en djupdykning i en 
texttyp som är vanlig inom socialtjänsten och är ett bra exempel på att socionomers skrivande är en integrerad del av det professionella arbetet, nämligen de barn- och ungdomsutredningar som socionomer gör vid anmälan om oro för ett barn. Syftet med dessa är att utreda och bedöma om barnets situation bör vara föremål för en myndighetsinsats av något slag; antingen en frivillig insats genom socialtjänstlagen, en tvångsinsats genom till exempel lagen om vård av unga eller, i de fall vårdnadsfrågan är under utredning, utgöra underlag för att bedöma vårdnadshavarnas föräldraskapsförmåga. Informationsinsamlandet som process och skriven produkt kan dels utgöra ett underlag för dialog med föräldrarna och andra i barnets närhet inklusive skola och andra myndigheter, dels kan texten ligga till grund för ett avgörande i domstol i de fall socialsekreteraren bedömer ett behov av en tvångsinsats.

En utredning av barn i fara består av en undersökningsprocess och en slutrapport, och båda är i stor utsträckning textbaserade på så sätt att det som skrivs under undersökningsprocessen löpande ska kommuniceras till klienterna och kan revideras inför slutrapporten. Den skrivna texten blir en del av interaktionen med klienterna under processens gång, och den färdiga rapporten ska kommuniceras både med klienterna och med andra aktörer.

\section{Processen}

När en anmälan om oro för barn i fara kommer in ska oron och misstanken att barnet far illa utredas, det vill säga att de relationer och miljöer som finns kring barnet ska värderas utifrån socialvetenskaplig kunskap om barns behov. En utredning av anmälan om barn i fara ska enligt lagen påbörjas skyndsamt och genomföras sakligt. Myndighetspersonerna i socialtjänstens processer har på ett annat sätt än en åklagare i rätten tolkningsföreträde i den situation som ska utredas, eftersom ingen försvarsadvokat finns med under insamlandet av kunskap som ligger till grund för bedömningen. Många viktiga faktorer vid bedömningar av föräldraförmåga kan bara uppfattas i direkt interaktion med eller vid observation av interaktion mellan förälder och barn i närvaro av myndighetspersoner, alltså i situationer som kan vara väldigt stressframkallande för de granskade personerna. Individer som har eller inte har sociala svårigheter av olika slag blir granskade i sitt innersta av personer som träffar dem vid tidpunkter och platser som de inte själva kan råda över.

Det finns här likheter med en polisiär utredning genom att det är viktigt att utreda vad som hänt och de inblandades avsikter, och att presentera informationen på ett sakligt och opartiskt sätt. Men det finns en väsentlig skillnad i att polisen och andra juridiska instanser kan sägas ha positivistiska krav på sanning: "har denna person utfört denna handling?" medan samhälls- och socialvetenskapen utgår från en mer socialkonstruktivistisk utgångspunkt, att verkligheten kan se väldigt olika ut sett ur olika perspektiv men att det trots det finns lidande och risker som myndighe- 
ter har etiska och lagliga krav att skydda människor från (se t.ex. Thorburn Stern \& Wikström, 2016).

Olikheterna mellan de båda sätten att se på världen ställer särskilda krav på socialsekreterares analys- och skrivförmåga. Både relationen mellan den utredande myndighetspersonen och de granskade personerna, de situationer där information samlas in, och bedömning av olika företeelsers betydelse för den sammantagna situationen, spelar roll för slutsatserna av bedömningen och i samtliga av dem måste socionomen agera medvetet och professionellt.

Interaktionen och maktrelationerna i utredningsfasen ställer stora krav på åtminstone fem saker i skriv- och analysprocessen (efter Edvardsson, 1991):
a. förståelse för att fenomen och situationer kan tolkas och uppfattas på olika sätt
b. förståelse för vilka perspektiv man själv använder i en given situation
c. kontinuerlig källkritik
d. aktiv och professionell självreflexion
e. tydlighet kring klienten/-ernas uppfattning om sakförhållanden.

Samtliga punkter kan kopplas till skrivande inom socionomutbildningen.

De förmågor som framhålls i punkterna a och b kan i ett utbildningssammanhang övas genom att i texter och analysuppgifter aktivt byta perspektiv eller analysvinkel. Därmed får studenten också tillfälle att utveckla en förståelse för att man alltid använder något perspektiv eller en analysvinkel när man betraktar och tolkar fenomen. De här två hör till de akademiska skrivkompetenser som tränas i metoduppgifter och uppsatser. Samhällsvetenskaplig metodologi vilar på insikten att insamling och tolkning av empiri inte kan göras neutralt utan påverkas av att medvetna och omedvetna perspektiv är akademiska analysfärdigheter som behöver appliceras på utredningsverkligheten. Att förstå sina egna och andras tolkningsramar och perspektiv, och att växla perspektiv aktivt, kräver förtrogenhet med socialvetenskapliga teorier och förmåga att använda dem. Färdigheterna att välja och använda teoretiska analysverktyg är inget akademiskt utanpåverk utan ett dagligt behov för socionomer. Här är det viktigt att akademin visar på kopplingen mellan det akademiska och det professionella för att ge de framtida socionomerna förmåga att söka ny och utvidgad kunskap, men också att hålla uppe trycket på arbetsgivarna att ge socionomerna utrymmet.

Den som samlar in och använder kunskap från olika källor: teoretisk litteratur, kollegers erfarenheter eller klienters uttalanden, behöver förmåga till kontinuerlig källkritik, punkt c. Alla källor och uppgiftslämnare har sina skäl att skriva eller uttala sig som de gör och ingen text eller tal finns i ett vakuum. Trovärdighet, perspektiv och relationer till andra texter eller uttalanden måste alltid beaktas när 
en professionell värdering av ett kunskapsunderlag görs. Även detta är en skrivkompetens som övas i en uppsatssituation, och en koppling som behöver lyftas fram aktivt.

Aktiv och professionell självreflexion, punkt d, är en analysfärdighet som skiljer sig från den traditionella akademiska verksamheten. Där ses ofta, men inte alltid, tydlig referens till forskarsubjektet som ett stilbrott och bristande vetenskaplighet. Inom socialkonstruktivistisk och feministisk forskningstradition (se t.ex. Johansson, 2005) understryks dock ofta vikten av att inkludera forskarjaget i analysen. En socionom använder i stor utsträckning sig själv som arbetsverktyg både genom målinriktad interaktion med klienter och genom sin professionella analytiska blick. Den "reflekterande praktikern" (Schön, 1983) är ett professionsideal som förutsätter snabb men professionell analys av det egna handlandet, en typ av analys som förutsätter akademiska analysfärdigheter i kombination med interaktionsfärdigheter och en förståelse för vad den egna närvaron som myndighetsperson innebär för de personer som blir betraktade och bedömda.

Självreflexion inbegriper också en insikt om vilka värderingar och fördomar man bär på. Att den myndighetsperson som ska göra bedömningar av andra människors styrkor, svagheter, problem och framtid inte ska ha fördomar låter som en självklarhet, men det finns många exempel på att det kan vara svårt i praktiken. Bo Edvardsson (se t.ex. 1991, 2014) nämner vikten av att ställa upp tydliga och motiverade frågeställningar i undersökningen och söka efter argument för och emot hypoteserna lika aktivt, för att undgå misstaget att söka stöd för tidigt gjorda antaganden eller outtalade förförståelser som kan grunda sig på personliga preferenser. För detta krävs både aktiv och strukturerad analys enligt punkt a, och aktiv självreflexion kring hur man som utredare betraktar och tolkar material till stöd eller som bevis mot hypoteser. Det är både en metodologisk och en etisk fråga. Större fokus på forskningsetik i socionomstudenters uppsatser skulle kunna ge viktig koppling till yrkesfärdigheter. Här behöver socionomstudenter både ha förtrogenhet med akademiska analysverktyg och akademisk diskurs där användningen av första person ofta ses som ett direkt stilbrott (se t.ex. Blückert, 2010), för att kunna överföra analysverktygen till den professionella diskurs där de som yrkesverksamma socionomer förväntas skriva in sig själva i sina texter (Rai \& Lillis, 2013).

Lagen kräver att de berördas synpunkter ska framgå tydligt av utredningsrapporten, punkt e. Uttalanden och uppgifter från de berörda personerna som refereras måste också godkännas av dem eller så måste alternativa uppfattningar redovisas. Att öppet redogöra för hur handlingar tolkas är en del av en akademisk hypotesprövning, och att göra sådana tolkningar i en text som de personer som granskas läser och ska godkänna kräver stort mått av professionell ödmjukhet. Även om reflexionerna av utredarens personliga roll $i$ analysen bör formuleras $i$ tredje person $i$ texten 
för att fylla kriterierna för ett professionellt språk måste det tydligt framgå i utredningsrapporten vad som är insamlade uppgifter, vad som är utredarens tolkning och om de berörda har avvikande tolkningar eller uppfattningar om sakförhållanden. Individreferat där man anger omständigheterna kring uttalanden och observationer är textdrag som liknar akademiska texter, som analys och diskussion av intervjumaterial $i$ en uppsats. Samtidigt utvidgas det akademiska draget genom att klientens/intervjupersonens röst blir tydlig inte bara som analysmaterial utan även som en direkt deltagare som godkänt eller motsagt analysen.

\section{Den färdiga rapporten}

Det faktum att en utredning också kan utgöra ett underlag till en juridisk process innebär att viktiga rättssäkerhetskrav ställs både på utredningsarbetet och på den text som processen utmynnar i. Till skillnad från andra underlag till juridiska processer, som polisundersökningar och liknande, innehåller socialtjänstens utredningar mycket information som är omöjlig att granska i efterhand. Medan polis och åklagare arbetar med tekniska bevis eller namngivna vittnens utsagor kan socialsekreterarens iakttagelser av eller interaktion med de inblandade personerna inte granskas av klienternas rättsliga företrädare, utan de har bara utredningstexten att förhålla sig till.

Att socialsekreteraren i de här fallen inte själv har beslutanderätt i ärenden innebär två saker rent språkligt: dels ställer det diskursiva krav på auktoritet som övertygar domstolen om utredarens professionalism utan att ge avkall på begriplighet gentemot klienterna, dels ställer det retoriska krav på att kunna framställa underlaget som en argumentation där för och emot ges lika stor plats. Friis menar i sin studie att utredningstexterna tenderar att förenkla komplexa problemsituationer och lägga stort fokus på faktorer som talar för att socialtjänstens bedömning är riktig (Friis, 2003 s. 265). De förenklade beskrivningarna och resonemangen i utredningstexterna kan tolkas som en konsekvens av att socionomernas kunskapsfält ofta betraktas som underordnat det juridiska kunskapsfältet (se t.ex. Winther Jørgensen, 2000): Den socialvetenskapliga kunskap som de använder för att dra slutsatser om barnets situation och föräldrarnas förmåga måste både förklaras för föräldrarna - som troligen gör helt andra bedömningar - och för tingsrätten. Utredningsrapporten måste därför balansera mellan alltför komplicerat språk som blir otillgängligt för klienterna, alltför vardagligt språk som inte signalerar professionell auktoritet, alltför djupgående socialvetenskapliga resonemang som tingsrätten inte tar till sig och alltför förenklade slutsatser som inte respekterar socialvetenskapens kunskapsgrund. God skrivförmåga och diskursmedvetenhet torde vara en fördel. 


\section{Slutsatser vad gäller målspråk och textfärdigheter}

För att sammanfatta: det socionomerna behöver ha med sig av språkliga färdigheter är både aspekter som hör till de akademiska diskurserna och skrivfärdigheterna, men också aspekter som utvidgar det akademiska språket på olika sätt:

Metod- och analysfärdigheter: Rättssäkerheten kräver noggrannhet, systematik och etik samt medvetenhet om och öppenhet i perspektivval och tolkningsprocess. Analys och perspektivval baseras på teoretisk kunskap som ibland kräver fackspråk och resonemang som inte hör till det vardagsspråk som klienterna förväntas behärska, och inte heller den allmänvetenskapliga eller juridiska diskurs som hör till domstolen. Här kan en paradox uppstå mellan kraven att aktivt använda socialvetenskaplig kunskap och analys, men inte kunna skriva ut den i rapporterna.

Källkritik: Alla källor, både skriftliga och muntliga, måste värderas och förstås i sitt sammanhang.

Professionell själureflexion: Eftersom socionomers professionella bedömningar kräver personlig närvaro och interaktion måste förståelsen av fenomen inkludera den egna närvaron och uppfattningsförmågan, vilken alltid är subjektiv men ändå ska vara professionell. Därför krävs aktiv självreflexion, vilket inkluderar löpande prövning av etiska ståndpunkter i relation till ny kunskap.

Saklig dialogicitet som är synlig $i$ texten: De uppgifter som används i en bedömning måste vara sakliga, och olika uppgifter måste vägas mot varandra med lika ansträngning för och emot. De uttalanden och uppgifter som refereras från de berörda personerna måste också godkännas av dem eller så måste alternativa uppfattningar redovisas.

Diskursmedvetenhet: Socionomer i myndighetsfunktion behöver skriva så att både klienter och myndighetspersoner förstår innehållet och uppfattar att det ligger en professionell bedömning bakom orden. Språket behöver förmedla professionalitet och samtidigt kommunicera både med klienterna och med eventuella jurister eller andra myndighetspersoner.

Samtliga punkter förutsätter akademiska skrivkompetenser men tar sig inte uttryck riktigt på samma sätt som i de traditionella metod- och uppsatskurserna inom högskoleutbildningen, vilket leder till att många studenter har svårt att göra kopplingen mellan de båda fälten.

\section{Skrivande och socialisation}

Att tillägna sig färdigheter som språk och skrivande är att förändras som människa i någon mån. Den professionella identitet som högre utbildning lägger grunden för utvecklas under hela yrkeskarriären. Academic socialization- och academic literacies-perspektiven, som nämndes i artikelns början, diskuterar vilken typ av socialisa- 
tion studenterna genomgår och/eller förväntas genomgå, men begränsar sig till den akademiska värld där huvuddelen av socionomstudenterna endast tillbringar några år. I en professionsutbildning ska ju merparten av studenterna inte insocialiseras i den akademiska miljön utan bara använda de akademiska verktygen som ett steg på vägen vidare mot en professionell miljö vars kontakter med den akademiska i praktiken är ganska begränsade.

Både studenter och professionella brukar beskriva studietidens kunskaper och färdigheter som något de unga professionella ska ha med sig, alltså ha införlivat för att sen kunna använda när de kommer ut i verkligheten. Men textfärdigheter utvecklas främst i den miljö där de används och upplevs relevanta, så relationerna kring texterna, kollegers och chefers förväntningar på en bra text, är troligtvis viktigare än de krav som har ställts under utbildningen.

Samtidigt är kraven på yrkesverksamma socionomers texter outtalade snarare än uttalade, och de direkta bedömningssituationer som den akademiska världen är full av finns inte alls. Om de akademiska textfärdigheterna beskrivs som en "hemlighetsstruktur" (Ask, 2007) med koder som bara syns när de bryts, kanske man kan tala om professionella textfärdigheter som osynliga när de är bra, och synliga som annat än just skrivkunskap när de är dåliga. Kritiken mot dåliga utredningar framkommer ibland i media och genom klientorganisationer, men kritiken mot utredningarna skiljer inte på olika dimensioner som bemötande, analys eller text.

De kontakter som finns mellan profession och akademi är viktiga, och det är viktigt att akademin tydliggör kraven på professionen - eftersom professionen inte alltid gör det själv. Forskare och lärare inom akademin problematiserar andra delar av det sociala arbetet och ställer krav på etisk medvetenhet, kritisk reflexion, arbetsgivarnas respekt för socionomernas kunskaper och så vidare. De kunskaper som utbildningsinstitutionerna förväntar sig av sina studenter är inte akademiskt distanserade utan bygger på krav sprungna ur analys av det sociala arbetet ur olika perspektiv. Men frågan är om de akademiska färdigheter som utbildningarna tränar studenterna i presenteras på ett sådant sätt att studenterna förstår att de inte bara är inomakademiska utan utgör förutsättningar för professionellt socionomarbete. Om akademins förväntningar på professionen hade varit tydligare för studenterna redan under utbildningstiden kunde kopplingarna mellan akademi och profession framstå klarare för dem.

Både analytiska färdigheter, källkritik och hantering av längre texter är viktiga byggstenar för en yrkesverksam socionom, liksom för alla andra professionella inom välfärdssektorn. Sammankopplingen av de akademiska och de professionella textformerna och identiteterna är därför också viktiga. 


\section{Vad görs inom programmet i dag?}

Genom socionomprogrammets sju terminer skriver studenterna mycket, men den pedagogiska medvetenheten om skrivande är ofta låg hos både lärare och studenter.

Progressionen i skrivutvecklingen kan inte handla om att studenterna först förväntas lära sig hantera det akademiska ytspråket för att sen gå vidare mot de mer djupgående akademiska färdigheterna. Texter har alltid både innehåll, form och kommunikativa aspekter på flera nivåer. De allra flesta studenter har med sig allmänna textfärdigheter in i utbildningen, medan de specifika diskursiva färdigheter och akademiska analytiska verktyg som är grundläggande för det professionella skrivandet behöver tränas genom hela utbildningen.

En genomgång av kursplanerna för de respektive terminerna på en av landets socionomutbildningar visar på främst tre typer av texter, för att hårdra. Dels finns tentamina som är nära kopplade till kurslitteraturen i de teoretiska kurserna, dels skriver studenterna under kurserna i personlig/professionell utveckling (PPU) tanketexter som kopplar teoretiska och färdighetstränande resonemang till personliga reflexioner och dels finns de "klassiska" längre studentuppsatserna mot slutet av utbildningen. Kortfattat kan vi säga att det akademiska skrivandet och (förhoppningsvis) metaspråket kring texter grundläggs på programmets första termin, och under termin två, tre och första halvan av termin fyra kommer studenterna i kontakt med olika akademiska diskurser. I slutet av termin fyra är första tillfället för en större egen akademisk text. Under "praktikterminen", termin fem, flyttas studenternas insocialisering till en professionell arena, men kopplingarna till akademin finns kvar. Och under termin sex och sju skrivs de större akademiska texterna. För att utveckla både academic och professional literacy måste vi göra kopplingarna genom hela utbildningen och fördjupa de kontakter mellan textformerna som finns i dag.

Diskursmedvetenhet och medvetenhet om textens kommunikativa funktion kan tränas i många olika sammanhang, särskilt om metakunskaperna följer med och om målbilden för texterna är gemensam för lärarna. De tre textformerna inom utbildningen tränar diskursmedvetenhet och kommunikation på olika sätt, och eftersom åtminstone PPU-texterna och uppsatserna har likheter med studenternas framtida professionella skrivande finns det gott om tillfällen att uppmärksamma skrivandet och utveckla ett metaspråk för det.

Om de stora, självständiga uppsatser som studenterna förväntas producera själva eller i liten grupp blir frånkopplade den professionella socialisationen så upplevs det akademiska arbetssättet skräckinjagande och kanske också omöjligt. Den modellinlärning av skrivande som de kan ha mött i kontakt med fältet, på studiebesök eller under praktikperioder, ger sällan grund för akademiska färdigheter såsom analys och källkritik, och det skrivande de möter på praktiken återkommer sällan eller aldrig inom utbildningens ram. 


\section{Avslutning}

Ett tydligare ömsesidigt befruktande mellan det akademiska skrivandet och det professionella kan vara en väg att gå. Men då gäller det också att se bredare och djupare på socionomens yrkesroll från att vara en handläggare på ett socialkontor till att bli en analytisk och kreativ problemlösare i den sociala verkligheten. Kontinuerligt lärande, kontinuerlig analys och kontinuerlig verklighetskontakt är viktigt både för professionella, högskolelärare och forskare. Socionomutbildningarna behöver därför:

- synliggöra kraven på socionomers professionella skrivande för undervisande lärare inom utbildningen

- synliggöra hur krav på akademiskt skrivande samspelar med de professionella kraven

- tydliggöra för studenterna och undervisande lärare hur olika delar av utbildningen tillsammans ger studenterna verktyg för akademiskt och professionellt skrivande.

Samhället behöver djup och bred professionalitet både inom socialtjänsten och inom andra välfärdsyrken. Socionomstudenterna är ambitiösa och kunniga. Om högskoleutbildningarna bättre kunde knyta ihop delarna till en helhet, och tydliggöra målet så att studenterna som framtida professionella kan se att utbildningen ger dem verktyg som sen från år till år fördjupas vidare, så hade vi haft en socionomkår som kunde skriva med den auktoritet som deras kunskaper förtjänar.

\section{Referenser}

Ask, S. (2007) Vägar till ett akademiskt skriftspråk. Akademisk avhandling. Växjö:Växjö universitet. http://urn.kb.se/resolve?urn=urn:nbn:se:vxu:diva-1276

Blückert, A. (2010) Juridiska - ett nytt språk?: En studie av juridikstudenters språkliga inskolning. Uppsala: Institutionen för nordiska språk, Uppsala universitet.

Edvardsson, B. (2014) På saklig grund: Utredningsarbete inom socialtjänsten. Malmö: Gleerups. Edvardsson, B. (1991) Punktlista för personbedömning och utredning. Örebro: Örebro universitet.

Friis, E. (2003) Sociala utredningar om barn: En rättssociologisk studie av lagstiftningens krav, utredningarnas argumentationer och konsekvenser för den enskilde. Lund: Sociologiska institutionen, Lunds universitet.

Graff, G. (2003) Clueless in academe: How schooling obscures the life of the mind. New Haven: Yale University Press.

Johansson, A. (2005) Narrativ teori och metod: Med livsberättelsen i fokus. Lund: Studentlitteratur.

Lea, M.R. \& Street, B.V. (1998) Student writing in higher education: An academic literacies approach. Studies in Higher Education, 23(2): 157-173.

Rai, L. \& Lillis, T. (2013) Getting it write' in social work: Exploring the value of writing in academia to writing for professional practice. Teaching in Higher Education, 18(4): 352-364. 
Schön, D.A. (1983) The reflective practitioner: How professionals think in action. New York: Basic Books.

SFS 2006:173. Högskolelag

Thorburn Stern, R. \& Wikström, H. (2016) Migrationsrätt: Skyddsbehov och trovärdighet: Bedömning i asylärenden. Stockholm: Liber.

Wingate, U. \& Tribble, C. (2012) The best of both worlds? Towards an English for academic purposes/academic literacies writing pedagogy. Studies in Higher Education, 37(4): 481-495.

Winther Jørgensen, M. (2000) Diskursanalys som teori och metod. Lund: Studentlitteratur. 